\title{
Design of a Virtual Reality device to motivate experiences of meaningful learning
}

of the Iberoamerican Society

of Digital Graphics

Medellin | Colombia

\author{
María José Appendino \\ UNL | Argentina | mjappendino@gmail.com \\ Lucía Carboni \\ UNL | Argentina | luciacarboni19@gmail.com \\ María Elena Tosello \\ UNL | Argentina | maritosello@gmail.com
}

\begin{abstract}
With the increasing popularization of technologies such as Augmented Reality -AR- and Virtual Reality -VR-, interest aroused in studying the incorporation of these media into design disciplines higher education. The main objective of this investigation was to integrate VR and $\mathrm{AR}$ into the lessons, in order to motivate a meaningful learning process for students. The project was developed for a subject corresponding to the first year of the university careers of Architecture, Visual Design, and Industrial Design. This device was effectively implemented for the dictation of virtual classes, in the context of the COVID-19 pandemic.
\end{abstract}

Keywords: Virtual Tour; Design Education; Emerging Technologies.

\section{INTRODUCCIÓN}

Con la evolución de las tecnologías digitales nos hemos habituado a la inmediatez, a la hiperconexión, y a un alto nivel de estímulos y de interactividad. La Realidad Aumentada (RA) y la Realidad Virtual (RV), ya desde hace algunos años, nos permiten experimentar ambientes mediados de manera innovadora e inmersiva.

Sin embargo, es común en la educación superior la tendencia a seguir utilizando materiales educativos que han presentado escasas modificaciones en las últimas décadas, sin considerar los cambios contextuales, situación que se detectó particularmente en los talleres para la enseñanza y el aprendizaje de la Arquitectura y el Diseño de la Facultad de Arquitectura, Diseño y Urbanismo de la Universidad Nacional del Litoral (FADUUNL).

Ante esta problemática, consideramos que los diseñadores tenemos la capacidad de realizar un aporte a través del diseño de recursos didácticos aumentados que incorporen tecnologías emergentes como la RA y la RV a los materiales educativos, transformándolos en inmersivos, multisensoriales e interactivos, para estimular el interés de los estudiantes por el conocimiento y propiciar procesos de aprendizaje significativos.

\section{METODOLOGÍA}

En primer lugar, se seleccionó el Taller Introductorio, correspondiente al primer año de las carreras de Arquitectura, Licenciatura en Diseño de la Comunicación Visual y Licenciatura en Diseño Industrial, para realizar el estudio de campo a través de observaciones con el fin de registrar los recursos didácticos implementados por los docentes y las respuestas de los estudiantes frente a ellos. En segundo lugar, se analizaron casos análogos, para lo cual se conformó un corpus de piezas que incluyó recursos que incorporan estas tecnologías en el ámbito educativo y también aplicaciones de RA y RV del ámbito del entretenimiento que propongan experiencias atractivas a sus usuarios. Luego, se elaboró un instrumento de análisis teniendo en cuenta diferentes categorías y variables a indagar, tales como la inmersividad que propician, la interactividad que proponen, el hardware que requieren, y los factores morfológicos y simbólicos. En tercer lugar, se diseñó un dispositivo, considerando las características del contexto analizado y las potencialidades tecnológicas identificadas en los casos análogos. El diseño incluyó un recurso de RA, uno de RV y un video $360^{\circ}$ y, hasta el momento, se ha desarrollado el recurso de RV.

\section{ESTUDIO DE CAMPO}

Para el estudio de campo, se visitaron las clases dictadas en los diferentes módulos que componen el taller (Fig. 1)

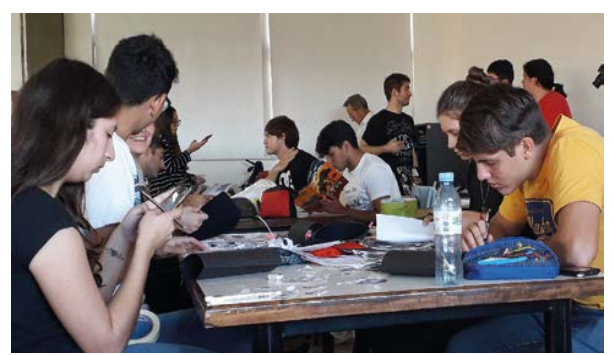

Figura 1: Estudiantes durante las clases prácticas. 
a fin de conocer, por un lado, los recursos didácticos que los docentes implementan en sus clases y que utilizan para la exposición y desarrollo de contenidos; y, por otro, el nivel de participación y respuesta por parte de los estudiantes.

Se observó que, en su mayoría, los profesores realizan el desarrollo de sus clases teóricas a través de exposiciones orales, utilizando generalmente el micrófono y caminando por el aula a fin de darle mayor dinamismo a la clase, con el objetivo de generar cercanía con los estudiantes realizando comentarios y preguntas. Sin embargo, en repetidas ocasiones se observó que los estudiantes no prestaban atención a la clase, muchos de ellos utilizaban el celular durante la misma, estaban recostados sobre los tableros o conversaban con sus compañeros y, ante las preguntas del profesor, muy pocos respondían.

Respecto a los recursos didácticos implementados, es constante la utilización de diapositivas con imágenes y texto, mientras que los recursos audiovisuales raramente son utilizados. Sólo algunas cátedras, con la colaboración de los pasantes en docencia, plantean actividades diferentes que rompen estas generalidades, como por ejemplo la demostración en vivo de técnicas de representación gráficas o la utilización de animaciones para explicar procesos de despliegue de una figura tridimensional. Sin embargo, estos ejemplos innovadores carecen de interactividad, es decir, son utilizados sólo con fines expositivos y los estudiantes no están invitados a intervenir, participar o colaborar en ellos. En todas las clases teóricas observadas, la única interacción que se propone es el intercambio oral con el profesor. Como resultado, los estudiantes presentan una gran pasividad limitándose sólo a la recepción de los contenidos.

Durante el desarrollo de las clases prácticas la situación es diferente, los estudiantes adoptan un rol activo en la producción de sus trabajos prácticos. En estas clases se observaron mayores interacciones de los estudiantes entre sí, con los docentes y los pasantes, ya que durante este tiempo producen maquetas, collages, croquis, láminas y/o monografías, y aprovechan a evacuar sus dudas para continuar el trabajo en sus hogares.

Una vez finalizadas las clases teóricas, se realizaron entrevistas a los estudiantes y se les ofreció la posibilidad de ver y experimentar aplicaciones con RA y RV (Fig. 2). En estos intercambios se pudo observar que los recursos tecnológicos que se les mostraban, despertaron su interés y muchos opinaron que la RA y la RV podian ser útiles para el desarrollo de los contenidos propuestos por los docentes.

\section{ANÁLISIS DE CASOS ANÁLOGOS}

En la etapa siguiente, se analizaron diferentes aplicaciones de RA y RV (Fig. 3 y 4) con el objetivo de conocer los avances existentes en este campo tecnológico. Se analizaron cinco aplicaciones y para su elección se tuvo en cuenta: que incorporen al menos una de las dos tecnologías estudiadas; que hayan sido producidas en los últimos cinco años, para poder investigar los últimos avances de estas tecnologías; que propicien experiencias interactivas, donde el usuario tome un rol protagónico; y que correspondan al ámbito lúdico y educativo, ya que las aplicaciones del ámbito del

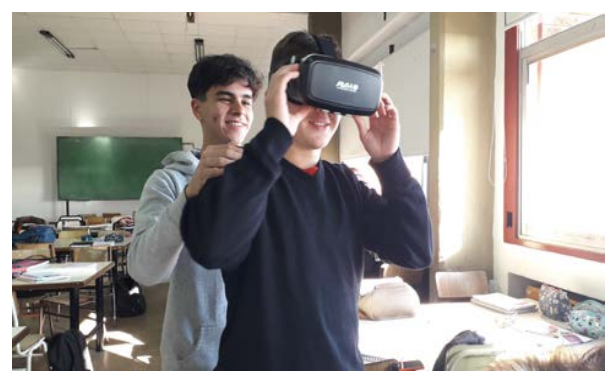

Figura 2: Estudiantes probando una app de RV.

entretenimiento presentan grandes desarrollos visuales y tecnológicos, y las del ámbito educativo permitirían establecer conexiones con el campo de aplicación del proyecto.

Las aplicaciones analizadas fueron:

- Little Mermaid: es un libro de cuentos que narra la historia de La Sirenita en la versión original de Hans Christian Andersen. Cuenta con una aplicación de RA para dispositivos móviles. Al apuntar las páginas del libro con un celular o tablet que contenga la aplicación, se puede visualizar un escenario en RA en el cual los usuarios pueden jugar y explorar. Es una producción del año 2016, de la editorial Books \& Magic de Dinamarca. Disponible en inglés y danés.

- Hypercubes: es una aplicación desarrollada en el marco de una tesis de Maestría en el Instituto Tecnológico de Massachusset (MIT) y propone una innovadora estrategia de enseñanza de la programación. Consiste en una aplicación de RA que se combina con cubos de papel, los cuales poseen diversos iconos que funcionan como trackers. A través del entorno físico, la creatividad y el juego, el usuario puede aprender conceptos básicos de programación y ver en RA los resultados de su interacción con los cubos y los parámetros que elige en la app. Fue desarrollada en el año 2018 por Anna Fuste Lleixá en Estados Unidos, como parte de un proyecto de investigación; actualmente no está disponible para ser descargada y utilizada.

- Google Expediciones: es una aplicación desarrollada por Google para realizar recorridos de RV o investigar objetos de RA. Cada objeto y recorrido aparece enriquecido con textos, voces y sonidos que dan cuenta del contenido que se quiere exponer. Esta plataforma permite organizar recorridos guiados para un grupo de personas conectadas a la misma red de WiFi. Asimismo brinda la posibilidad de visualizar el contenido y realizar recorridos de forma individual. Lo interesante de esta app es que puede vincularse con otras aplicaciones de la suite de Google que enriquecen la experiencia y permiten la creación de contenido por parte del usuario. Fue lanzada en 2016, está disponible en más de 20 idiomas. Corresponde al ámbito educativo y pueden disfrutarla tanto niños como adolescentes y adultos.

- VR Noir: es una experiencia de RV que consiste en un thriller interactivo. El usuario interpreta a una detective privada que debe resolver un enigma a través de los diversos niveles del 

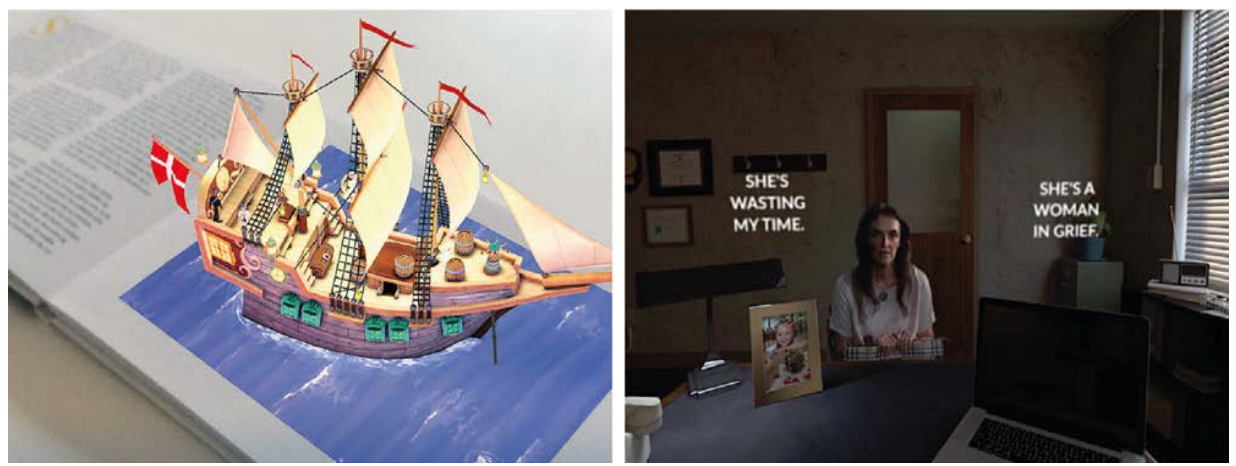

Figura 3: Casos analizados. Izquierda: Little Mermaid, derecha: VR Noir.

juego. Incluye los recursos de voz en off, sonido ambiente y videos $360^{\circ}$, lo que aumenta la inmersividad de la experiencia. Consiste en una app para smartphones, ya que necesita que dicho celular se complemente con lentes de RV. Está disponible para Android, iOS y Oculus. Es una producción del año 2016, desarrollada por la empresa australiana Start Vr. Disponible únicamente en inglés.

- APPrender Malvinas: consiste en un recurso didáctico sobre las Islas Malvinas. Mirando el mapa impreso a través de la aplicación de RA, es posible explorar diferentes aspectos históricos, geográficos y políticos de las Islas Malvinas. Además la misma información se encuentra disponible en una plataforma online. Fue lanzada en el año 2019 por el Gobierno de la Provincia de Santa Fe, Argentina. Incluye tecnología de RA y de RV, corresponde al ámbito educativo y está destinada principalmente a niños y adolescentes.

A través del uso de las aplicaciones, el análisis y la comparación de las mismas, se pudieron extraer algunos criterios que pueden ser tenidos en cuenta al momento de diseñar experiencias con RA y RV para el ámbito educativo. A continuación, recuperamos los más relevantes.

Las aplicaciones con fines lúdicos y recreativos presentan un alto desarrollo estético; esto puede deberse, por un lado, a que las empresas que los desarrollaron invirtieron un capital importante en su producción; y, por otro lado, a que pertenecen a países donde la trayectoria en RV y RA es más amplia. Teniendo en cuenta esto, es importante prever, en lo posible, una gran riqueza visual en el desarrollo de un proyecto educativo con RA y RV, debido a que hoy en día compite con producciones muy ricas del campo lúdico, y la audiencia buscará lo mismo en un material que incorpore estas tecnologías.

Al considerar los recursos visuales, también es importante destacar que la coherencia entre los distintos elementos propicia una imagen de unidad y ayuda al usuario a comprender mejor la interfaz. En la elección de los iconos para identificar acciones o tipos de información, es enriquecedor que los mismos estén en concordancia con la metáfora que plantea la narrativa o que al menos retomen metáforas visuales comunes o populares, por ejemplo: $x=$ cerrar; basura=eliminar. Estos detalles colaboran en la construcción de la coherencia visual, facilitan el uso de los dispositivos y brindan una experiencia enriquecedora.

Es importante destacar que las producciones de RV relevadas, presentan escenarios que guardan estrecha relación con la realidad, ya sea que éstos fueran producidos digitalmente o filmados con videos $360^{\circ}$. En base a esta recurrencia, se debe tener especial cuidado en lograr representaciones adecuadas, sin defectos que distraigan al usuario de la experiencia inmersiva que está viviendo.

En el juego VR Noir se utiliza el recurso de la voz en off para caracterizar el pensamiento del actor principal, que es el que personifica el jugador. Este recurso, sumado a la interacción que realizan otros personajes con el jugador, ayuda a potenciar la inmersividad en la narrativa, ya que la propuesta no es que el usuario sea un simple observador, sino que su participación sea continua en el desarrollo de la historia. Asimismo, cuando el tono comunicacional es informal y directo hacia el usuario, las indicaciones y las tareas se identifican como personales, lo que aumenta la inmersividad y el compromiso por parte del usuario.

Una característica presente en la mayoría de los casos, es que no se exponen amplias reglas o instrucciones, sino que se utilizan estrategias visuales y sonoras para indicar los recorridos y los objetivos. Así, toman relevancia los videos introductorios o explicativos, la comunicación a través de íconos que indican el objeto que hay que encontrar o la acción que se puede realizar, y las indicaciones mediante sonidos o voces. Cabe destacar que esto es posible porque se considera una audiencia que tenga una actitud exploratoria y que presente una predisposición a la prueba y el error, experimentando y explorando hasta que consiguen entender las distintas lógicas de las apps. Si la audiencia no presenta estas actitudes previamente, puede encontrarse con mayores dificultades para disfrutar la experiencia debido a que pueden tardar más tiempo en descubrir qué hacer. 

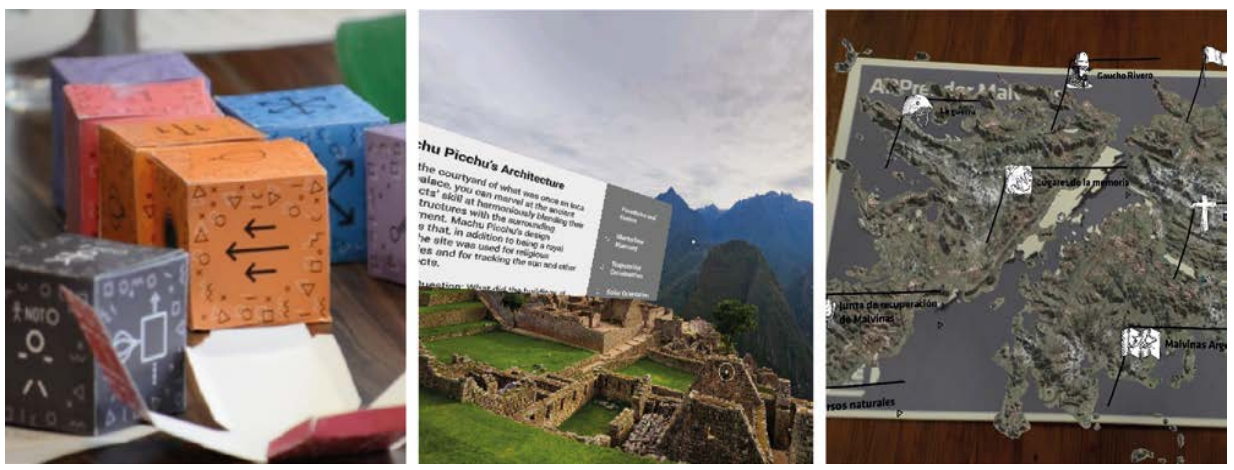

Figura 4: Casos analizados. Izquierda: Hypercubes, centro: Expediciones, derecha: APPrender Malvinas.

También podemos destacar, en relación a esta idea del usuario explorador, que una característica presente en todos los casos analizados es que no tienen pautado un único modo de recorrer la información, sino que se le permite al usuario buscar su propio camino. Esto brinda al sujeto un alto nivel de libertad para recorrer el contenido y la información según sus gustos y preferencias.

Otro criterio extraído del análisis consiste en la importancia de brindarle al usuario un preciso y completo feedback o retroalimentación de sus acciones, ya que es el modo en el que puede comprender más a fondo cada parte de la interfaz. Es decir, es importante que el usuario comprenda en todo momento qué es lo que está pasando, por ejemplo: si tiene que esperar, si debe continuar o si debe tomar decisiones.

Respecto a los factores de interacción y los diversos tipos de navegación, a través del análisis se comprobó que cuando se simplifican los elementos y acciones, o se incorporan similitudes visuales con otras aplicaciones que el usuario ya conoce, se reduce el tiempo de aprendizaje, y se posibilita una experiencia más agradable.

A su vez, cuando la interfaz incorpora puntos de referencias estables y la retroalimentación está correctamente visualizada, la navegación se vuelve intuitiva. De aquí que un diseño de interfaz claro y ordenado facilita la lectura de los elementos y su reconocimiento; y, por lo tanto, propicia una experiencia de usuario agradable.

En cuanto a los aportes de la RV y la RA, mediante el análisis de los casos corroboramos que, al incorporar estas tecnologías, el usuario puede acceder a experiencias y fenómenos que no están a su alcance; ampliar las posibilidades de interacción; y propiciar escenarios inmersivos que pueden ser aprovechados para motivarlo. En síntesis, el valor agregado que aportan radica en mostrar de una manera nueva y enriquecida, adaptada a los cambios culturales y a los desarrollos tecnológicos de la actualidad, el mismo contenido que antes los usuarios podían encontrar en dispositivos o experiencias analógicas.

\section{DISEÑO DEL DISPOSITIVO}

Luego de estudiar casos análogos y conocer el contexto donde se realizaría el proyecto, comenzó la etapa de diseño del dispositivo. Éste fue pensado para ser implementado en el Taller de Diseño Básico, uno de los módulos del Taller Introductorio común a las carreras de Arquitectura y Diseño, que se dicta en el primer año de éstas. Se seleccionó específicamente la temática de la ciudad como contenido principal, ya que en la asignatura se concentra un gran desarrollo teórico-práctico referente a este tema. El recurso didáctico que se diseñó está orientado principalmente a complementar la explicación de estos conceptos a los estudiantes y no pretende influir en las estrategias de realización de los trabajos prácticos.

Se diseñó un recorrido de RV (Fig. 5), pensado como un recurso didáctico que brinda una visualización completa del espacio que se debe analizar durante el cursado de la asignatura, junto con un anclaje teórico. Este recorrido se generó a partir de la plataforma Tour Creator y se visualiza en la aplicación Expediciones de Google. La plataforma Tour Creator ofrece la posibilidad de utilizar escenas y puntos de interés para crear los recorridos.

Las escenas se conforman con una imagen $360^{\circ}$, y pueden contener sonido ambiente. A su vez, en cada punto de interés se pueden incorporar imágenes, textos y narraciones.

Con respecto a los entornos $360^{\circ}$, que son la base de cada escena del recorrido, la plataforma posibilita usar una foto de $360^{\circ}$ de Google Street View, o cargar entornos $360^{\circ}$ o $180^{\circ}$ de producción propia. Se decidió utilizar fotografías propias, ya que esto posibilitaba realizar ediciones digitales que sirvieran a los fines comunicacionales. Para la captura de las fotografías de día, se utilizó una cámara Samsung Gear $360^{\circ}$, y las fotografías de noche fueron tomadas con un celular y la aplicación Street View, que permite capturar y generar fotos $360^{\circ}$. Luego de la captura de las imágenes, se

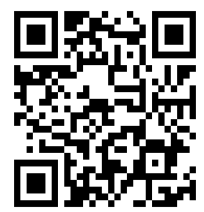

Figura 5: QR para acceder al recorrido virtual. 


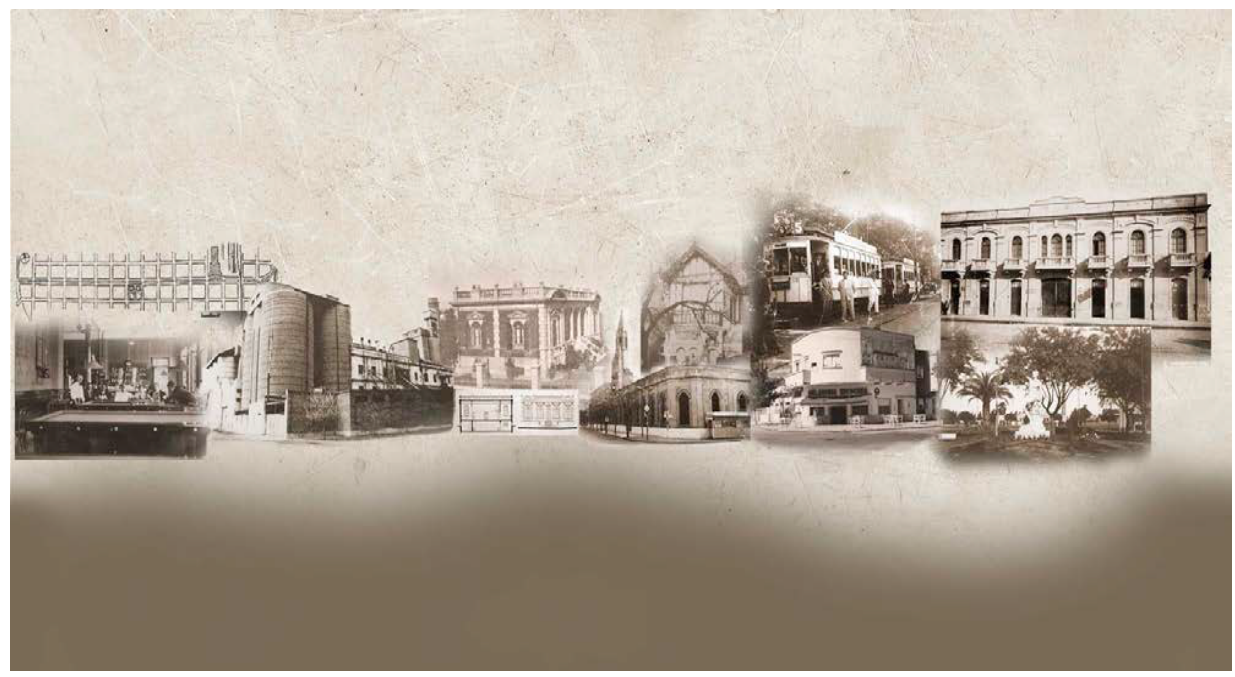

Figura 6: Entorno $360^{\circ}$ de la escena "Boulevard Histórico".

realizó un retoque digital de las mismas utilizando Photoshop. En este proceso se equilibraron colores, brillo, contraste, saturación, y se corrigieron imperfecciones o detalles, como por ejemplo se borró el trípode utilizado o los pies de la persona que tomó la fotografía, en el caso de las capturas con el celular.

Además, en algunas escenas se realizaron ediciones de mayor profundidad con el fin de que la imagen del entorno ayudara a reconocer y entender mejor los conceptos que en ella se presentan. Por ejemplo, en la primera escena se realizó una mixtura entre dos fotos del mismo lugar, una de día y una de noche, de modo que la mitad del entorno $360^{\circ}$ remite a un horario y la otra mitad a otro, con la idea de facilitar la comprensión de los cambios que se producen en la ciudad en diferentes momentos del día y comunicar que el sector analizado tiene vida y actividades tanto de día como de noche y en cada uno de ellos se presentan particularidades.

El recorrido completo está conformado por 9 escenas. La escena inicial se titula "Bienvenidos!" y en ella se introduce a los estudiantes en el recorrido y se enumeran aspectos generales del paseo. La escena 2, "Cada rincón cuenta una historia", busca vincular aspectos de la historia del sector con las actividades actuales que allí se desarrollan. Luego, se hace foco en dos sectores relevantes para el trabajo práctico: el Molino Franchino y la Plaza Pueyrredón. La escena 3, llamada "El Molino Harinero", recupera aspectos de la historia del lugar y narra el proceso de transformación del mismo hasta convertirse en lo que es hoy, y la escena 4 denominada "El Molino para todos", muestra la transformación del espacio al caer la noche, remarcando los aspectos morfológicos y materiales del molino. Después, se presenta la Plaza Pueyrredón a través de tres escenas, y cada una de ellas hace hincapié en un aspecto diferente de la misma. "La Plaza del Boulevard", remarca el hecho de que es la única plaza del recorrido; la escena "La Plaza de los Artesanos" destaca una actividad que allí se realiza y por la cual el lugar es reconocido; y la escena "La Noche de la Plaza" resalta los cambios en la apropiación del espacio en diferentes momentos del día. Luego, el estudiante se encuentra con dos escenas que buscan dar un cierre al recorrido, en primer lugar: "Boulevard Histórico", que muestra una colección de fotos históricas y explica diversos aspectos del Boulevard en el pasado, y por último "Recapitulemos" en la cual se recorre a través de cinco puntos de interés los aspectos más relevantes abordados en el recorrido, reunidos a modo de síntesis. Estas dos últimas escenas no refieren a entornos reales, sino que fueron generadas de modo completamente virtual. En el caso de "Boulevard Histórico" (Fig. 6), se realizó un collage de fotografías antiguas, y en el caso de la escena final "Recapitulemos" se pretendió que el entorno no llame la atención, ya que lo más importante era el resumen de contenidos. Por este motivo, se desenfoco la fotografía base y se incorporó un texto en forma de título al cual anclar la vista inicial.

Para los puntos de interés, se seleccionaron imágenes y textos. Se conformaron dos tipologías de imágenes distintas, por un lado, se generaron esquemas realizados con vectores para señalar conceptos abstractos como: línea, plano, volumen, simetría, etc., o para delimitar un canal o marcar un eje (Fig. 7). En algunos entornos, los esquemas se realizaron para ser vistos sobre la imagen $360^{\circ}$, mientras que en otros momentos, estas marcas se realizaron sobre fotos recuperadas de Internet.

Para realizar estos esquemas y para adicionar palabras en algunas imágenes, se conformó una paleta de colores y se seleccionó una fuente tipográfica. Para realizar esto, se consideró la identidad que ya brinda la plataforma Expediciones para desarrollar un estilo que se complemente con ella. Por otro lado, en la mayoría de los puntos de interés se adicionaron imágenes conformadas por distintas fotos, tanto actuales como históricas (Fig. 8).

Además, para la descripción de cada escena se decidió elaborar un texto breve, en un tono sencillo, cercano y directo que tiene como fin introducir a los estudiantes en la escena y dar una idea de lo que encontrarán allí. A su vez, se decidió aprovechar la posibilidad de agregar 


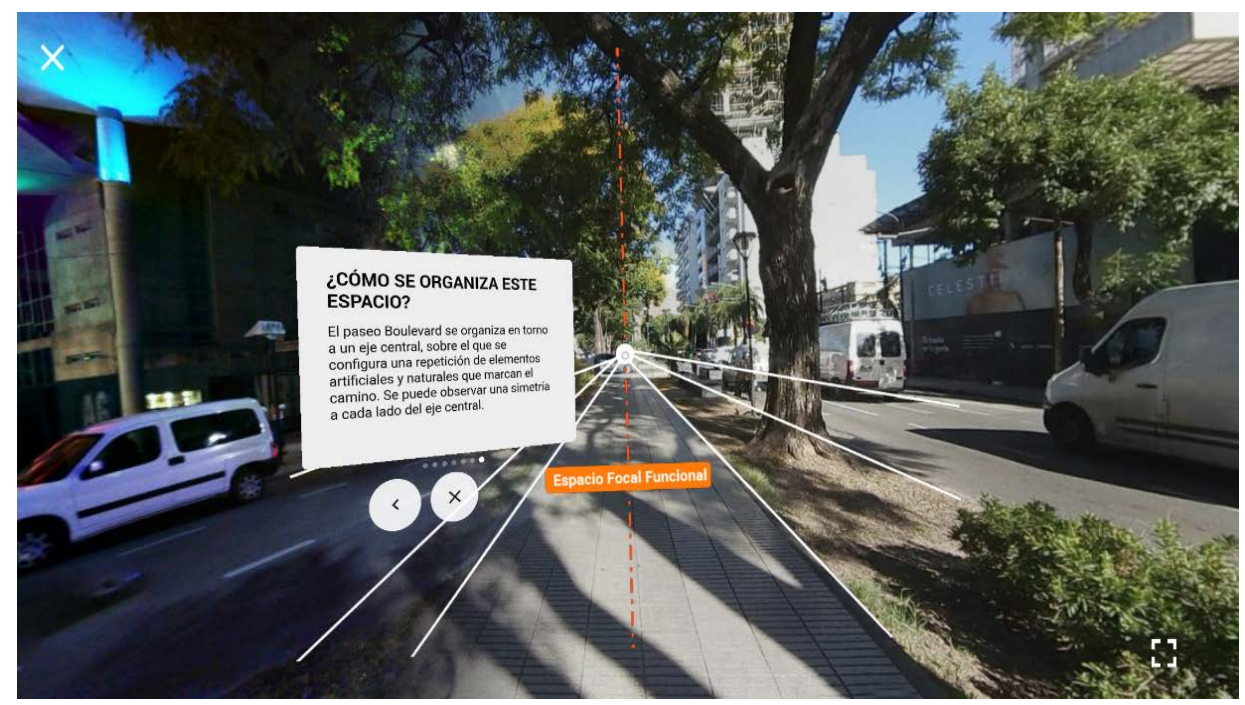

Figura 7: Con los esquemas vectoriales se señala, por ejemplo, el eje de simetría que ordena el sector analizado.

narraciones incorporando una voz en off que representara el papel de un guía e introdujera cada escena del recorrido. Esta voz en off es siempre de la misma persona, y se configura como un personaje que acompaña al usuario a lo largo de la experiencia.

Además, para la descripción de cada escena se decidió elaborar un texto breve, en un tono sencillo, cercano y directo que tiene como fin introducir a los estudiantes en la escena y dar una idea de lo que encontrarán allí. A su vez, se decidió aprovechar la posibilidad de agregar narraciones incorporando una voz en off que representara el papel de un guía e introdujera cada escena del recorrido. Esta voz en off es siempre de la misma persona, y se configura como un personaje que acompaña al usuario a lo largo de la experiencia.

Asimismo, se incorporó en cada escena un sonido ambiente que ayuda a reconstruir y reconocer el lugar, y posibilita a los estudiantes la percepción de las diversas atmósferas. Para esto, se definió qué tipo de sonidos corresponden a cada escena considerando las distintas actividades que allí se realizan. Para generar estos sonidos se combinaron en una sola pista de audio diversos sonidos y efectos de sonido particulares, a fin de recrear lo más fielmente posible las características sonoras del lugar.

\section{RESULTADOS}

La situación que se presentó durante los meses previstos para la implementación del dispositivo, fue distinta a la esperada, ya que en el mes de marzo de 2020 se desató la pandemia de COVID-19. Ante este evento, y debido a las medidas de aislamiento social decretadas por el gobierno nacional, la Universidad Nacional del Litoral decidió virtualizar los espacios curriculares y continuar con un dictado de clases en forma no presencial. En este contexto, se decidió utilizar el recorrido "Paseo Boulevard" como recurso didáctico digital para abordar los contenidos del Taller de Diseño Básico. El recorrido de RV complementó otros recursos como el apunte de cátedra y la explicación de los docentes.

Debido a la virtualización de las clases y al hecho de no poder estar en contacto físico con los estudiantes para explicarles cómo descargar el material en sus celulares, se decidió elaborar dos videos instructivos que contuvieran indicaciones para descargar el material, y todas las explicaciones pertinentes para su correcta utilización.

Los profesores publicaron todo el material en el entorno virtual para que los estudiantes pudieran visualizar la experiencia. Luego de visualizar el recorrido, acceder al material teórico, y contar con clases de consulta virtuales con sus docentes, alrededor de 120 estudiantes pudieron elaborar el TP 'Análisis de la vida urbana'.

\section{ENCUESTAS A DOCENTES Y ESTUDIANTES}

Luego de la implementación del material didáctico de RV, y debido a que no se pudo realizar una observación de la experiencia de los alumnos y docentes, se elaboraron dos encuestas para evaluar el recurso: una de ellas dirigida a los estudiantes, la cual tenía como principal objetivo conocer la experiencia que ellos habían tenido con el recorrido; y otra para los docentes que implementaron el recurso en sus clases, la cual tenía como principal objetivo recabar su opinión sobre los aspectos morfológicos y técnicos del recurso y a su vez, saber si constituyó un aporte a sus clases.

A los estudiantes se les envió a través de WhatsApp una encuesta de Google Form y se registraron 25 respuestas. Se observó que la mayoría de los estudiantes no visualizó el recorrido con un cardboard u otro tipo de casco de RV. En gran parte esto se debe a que la experiencia no se presentó en el aula y por lo tanto no se les pudo dar a los estudiantes los visores de RV, como estaba previsto. Debido a esto, no se comprobó de manera óptima la inmersividad del recorrido, sin embargo, se registró que 


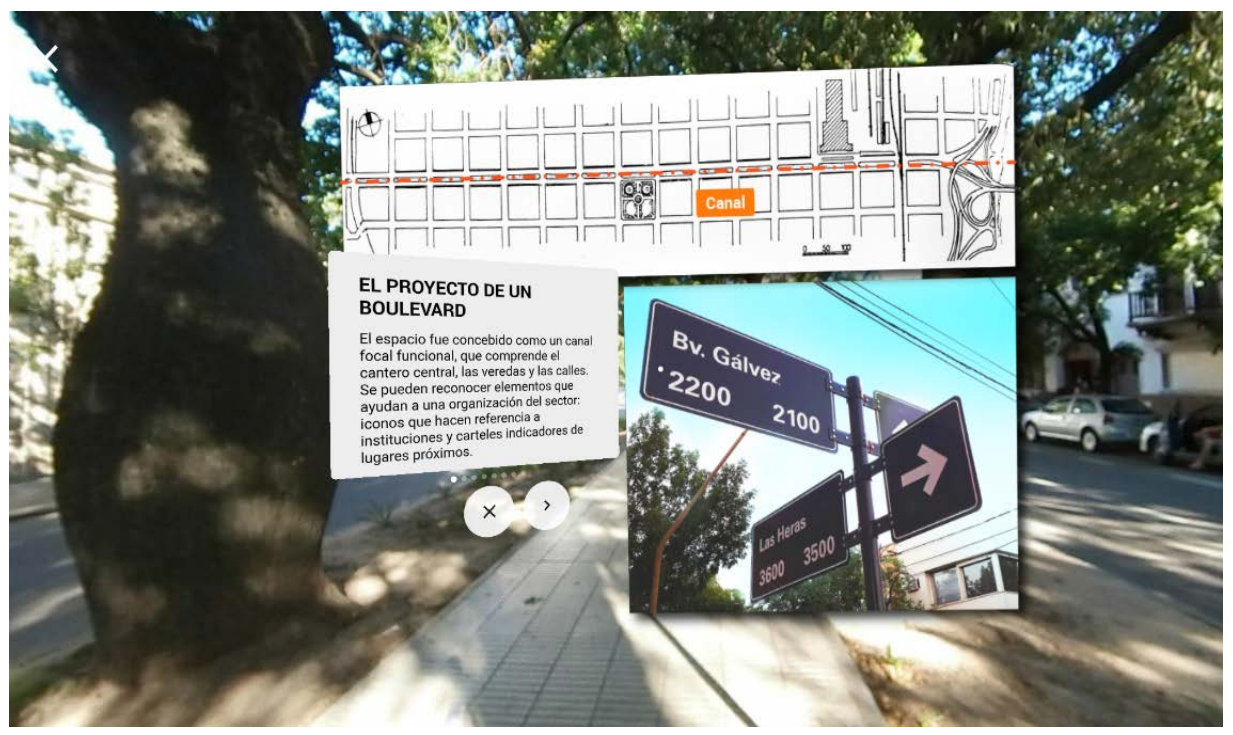

Figura 8: Las fotos, actuales e históricas, de producción propia o descargadas de la web, se utilizaron para ilustrar los distintos puntos de interés en el recorrido.

los estudiantes -en general- aprovecharon y consideraron satisfactoria la experiencia. Además, comentaron que les parece muy interesante la incorporación de este tipo de propuestas en el ámbito académico y calificaron la experiencia como muy atractiva y útil en general. Esto podemos verlo en los resultados obtenidos en la pregunta "¿Cómo consideras estas tecnologías para desarrollar contenidos académicos? (Fig. 9). Al indagar sobre las razones para considerarla atractiva y útil, ellos mismos expresaron afirmaciones como las siguientes:

- "Porque es una manera didáctica de aprender"

- "En la situación que estamos atravesando, creo que fue otra herramienta que nos ayudó a poder llevar a cabo los tp. Asique para mi fue fundamental"

- "Porque te hace meter y concentrar completamente en lo que estás visualizando, formas parte de la experiencia. $Y$ es mejor aprender asi."

- "Porque ya que hoy en día no podemos salir a la calle a observar nosotros mismos el lugar con la realidad virtual es algo que se acerca a la realidad."

- "Más allá de que transmitía a medias lo que sucede en bv. Esta bueno comenzar un trabajo a través de una actividad así de dinámica. Causa más entusiasmo o nuevos puntos de vista para por ejemplo en este tp: las atmósferas. Además re sirvió para los chicos q no eran de acá"

De todas formas, no se puede ignorar que esta percepción no fue unánime y algunos estudiantes expresaron que no tuvieron una experiencia totalmente inmersiva. Más allá de que no se pretende reemplazar la experiencia de encontrarse físicamente en el sector, se considera que estos resultados se deben a que muchos estudiantes no experimentaron el recurso con un visor de
RV, lo que hubiera aumentado la sensación de inmersividad. Sin embargo, se reconoce que el recurso condensa sólo una parte de las experiencias sensoriales y deja afuera otras como las olfativas, o la percepción de las texturas y las temperaturas con el tacto, y esto disminuye la sensación de realidad o inmersión.

Otras observaciones significativas refieren al acceso y la navegación dentro de la app, donde en general no se registraron inconvenientes, más que algunos retrasos en la carga del contenido. Consideramos que la demora en la carga se pudo deber a la conexión de internet, pero también puede haber influido el peso del archivo. Con respecto a las instrucciones, se comprobó que en general fueron claras y de gran utilidad. La experiencia fue bien calificada por la mayoría de los estudiantes.

Por último, se registraron 3 respuestas por parte de los docentes, quienes coinciden que el recurso es atractivo, estimulante y que se logra una sensación de inmersión en el entorno a través de él. A nivel formal, el recurso les resultó adecuado y atractivo, y se valoró mucho el tono comunicacional directo a los estudiantes. Asimismo, coinciden en afirmar la claridad y la pertinencia de los videos tutoriales. Además, es importante destacar que lo consideran adecuado para abordar los contenidos de la asignatura y que este recurso propició un mayor interés de los estudiantes en la resolución del TP, colaborando así en la realización del mismo, especialmente en el contexto de la pandemia por el COVID-19, donde no se pudo asistir a clases presenciales y recorrer el entorno. Cabe destacar que su implementación fue acompañada de otros recursos didácticos, como las clases virtuales por videoconferencia, la plataforma de Google Maps, imágenes, videos y fotos. Es la opinión de estos docentes que el Paseo Boulevard $360^{\circ}$ se complementa adecuadamente con estos recursos. 


\title{
¿Cómo consideras esta tecnologia para desarrollar contenidos académicos?
}

\author{
25 respuestas
}

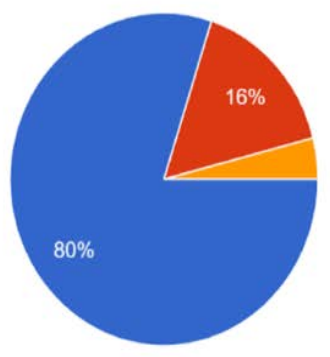

Muy atractiva y útil para comprender los contenidos

Poco atractiva y útil para comprender los contenidos

No la considero atractiva ni útil para comprender los contenidos

Figura 9: Resultado de una de las preguntas realizadas a los estudiantes en su respectiva encuesta, luego de la utilización del recurso virtual.

\section{DISCUSIÓN}

Esta investigación tenía como principal objetivo diseñar un dispositivo didáctico aumentado, basado en tecnologías emergentes como la RA o la RV, y en esta producción corroborar que el Diseño de la Comunicación Visual puede cumplir un rol protagónico, haciendo estas experiencias didácticas más atractivas y significativas para los estudiantes y generando de esta manera un aporte al ámbito educativo. Sin embargo, durante el proceso de prueba del dispositivo diseñado se comprobó algo aún más interesante, y es que si la situación lo requiere, el diseño puede colaborar en la adaptación del hombre frente a profundas crisis.

A partir del dispositivo diseñado, se pudo demostrar que una experiencia de RV puede brindar a los estudiantes la posibilidad de recorrer un sector de la ciudad como si estuvieran visitándolo físicamente, pero haciéndolo desde sus hogares. Además, la travesía virtual, al incluir textos, imágenes, narraciones y sonidos digitales, despliega los contenidos de manera enriquecida, propiciando una percepción aumentada, inmersiva e interactiva del espacio.

Vemos que el Diseño de la Comunicación Visual puede constituir un factor clave en las emergencias que se presentan, como esta situación de pandemia. En este caso particular, nuestro dispositivo ayudó a que los estudiantes pudieran cursar la asignatura y desarrollar el trabajo práctico a pesar de no poder recorrer la ciudad en forma presencial, accediendo a los contenidos interactiva y dinámicamente. De esta forma, realizamos un aporte a la educación universitaria, favoreciendo la continuidad de las actividades educativas y colaborando a que los estudiantes no perdieran el cuatrimestre de cursado en un momento de incertidumbre para toda la humanidad.

\section{REFERENCIAS}

Agamben, G. (2011). ¿Qué es un dispositivo? Sociológica, 26 (73), pp. 249-264.

Coates, K. y Ellison, A. (2014). Introducción al diseño de información. Badalona, España: Parramón.

Escamilla, J., Venegas, E., Fernández, K., Fuerte, K., Román, R. Abrego, G., Murillo, A., Guijosa, C. (2017). Realidad aumentada y virtual. EduTrends. Retrieved from https://observatorio.itesm.mx/edu-trends-realidad-virtual-yrealidad-aumentada/

Frascara, J. (2011). ¿Qué es el diseño de información? Buenos Aires, Argentina: Infinito.

Garret, J. J. (2011). Elements of User Experience: User-Centered Design for the Web and Beyond. California: New Readers Press.

Manresa Yee, C., Abásolo, M. J., Más Sansó, R., y Vénere, M. (2011). Realidad virtual y realidad aumentada. Interfaces avanzadas. La Plata, Argentina: Universidad Nacional de la Plata.

Mazzeo, C. y Romano, A. M. (2007). La enseñanza de las disciplinas proyectuales. Buenos Aires, Argentina: Nobuko.

Sanjurjo, L. y Vera, M. T. (1994). Aprendizaje significativo y enseñanza en los niveles medio y superior. Rosario, Argentina: Homo Sapiens Ediciones. 